\title{
Ulcerative Colitis in a Southern European Country: a National Perspective
}

\author{
Francisco Portela, MD, ${ }^{1,2+}$ Fernando Magro, PhD, ${ }^{1,3,4+}$ Paula Lago, MD, ${ }^{1,5}$ José Cotter, MD, ${ }^{1,6}$ \\ Isabelle Cremers, $M D_{1}^{1,7}$ João de Deus, MD, ${ }_{1}^{1,8}$ Ana Vieira, MD, ${ }_{1}^{1,9}$ Horácio Lopes, MD, ${ }^{1,10}$ \\ Paulo Caldeira, MD, ${ }^{1,11}$ Luisa Barros, MD, ${ }^{1,12}$ Jorge Reis, MD, ${ }^{1,13}$ Laura Carvalho, MD, ${ }^{1,14}$ \\ Raquel Gonçalves, MD, ${ }^{1,15}$ Mário J. Campos, MD, ${ }^{1,16}$ Paula Ministro, MD, ${ }^{1,17}$ Maria A. Duarte, MD, ${ }^{1,18}$ \\ Jorge Amil, MD, ${ }^{1,3}$ Susana Rodrigues, MD, ${ }^{1,3}$ Luís Azevedo, MD, ${ }^{1,19}$ and A. Costa-Pereira, PhD ${ }^{1,19}$
}

\begin{abstract}
Background: The incidence, prevalence, and even the clinical behavior of ulcerative colitis (UC) are highly variable in different world regions. In previous studies, Portugal was reported as having a milder clinical behavior. The aim of this study was to apply the Montreal Classification in a large group of UC Portuguese patients in order to describe their clinical characteristics and evaluate variables potentially useful for outcome prediction.
\end{abstract}

Methods: A cross-sectional study based on data collected from a nationwide online registry was undertaken.

Results: In all, 2863 patients with UC were included. Twentyone percent had ulcerative proctitis, 52\% left-sided colitis, and $28 \%$ extensive colitis. Sixty percent of patients had taken steroids, $14 \%$ immunosuppressors, $1 \%$ biologicals, and $4.5 \%$ were submitted to surgery. Patients with extensive colitis had more severe activity, needing more steroids, immunosuppressors, and surgery. At the time of diagnosis $61 \%$ were less than 40 years old and $5 \%$ less than 16. Younger patients also had a more aggressive initial course. Thirty-eight percent of patients had only taken salicylates during the disease course and were characterized by a lower incidence of systemic symptoms at presentation $(3.8 \%$ versus $8.8 \%$,

Received for publication August 12, 2009; Accepted August 29, 2009.

From the ${ }^{1}$ Portuguese Study Group of Inflammatory Bowel Diseases (GEDII), ${ }^{2}$ Hospitais da Universidade de Coimbra, ${ }^{3}$ Hospital de São João, ${ }^{4}$ Faculty of Medicine, University of Oporto, ${ }^{5}$ Hospital Geral de Santo António, ${ }^{6}$ Centro Hospitalar do Alto Ave, ${ }^{7}$ Hospital de S. Bernardo, ${ }^{8}$ Hospital Amadora Sintra, ${ }^{9}$ Hospital Garcia de Orta, ${ }^{10}$ Hospital das Caldas da Raínha, ${ }^{11}$ Hospital de Faro, ${ }^{12}$ Centro Hospitalar do Tâmega e Sousa, ${ }^{13}$ Hospital Pulido Valente, ${ }^{14}$ Hospital de Vila Real, ${ }^{15}$ Hospital S. Marcos, ${ }^{16}$ Centro Hospitalar de Coimbra, ${ }^{17}$ Hospital S. Teotónio, ${ }^{18}$ Hospital do Divino Espírito Santo, ${ }^{19}$ Departamento de Bioestatistica e Informática Médica, Faculdade de Medicina, Universidade do Porto, Portugal.

${ }^{\dagger}$ The first and second authors had equal contribution in the design and elaboration of the study.

Reprints: Francisco Portela, MD, Serviço de Gastrenterologia, Hospital Universidade de Coimbra, 3000 Coimbra, Portugal (e-mail: fasportela@ gmail.com)

Copyright (C) 2009 Crohn's \& Colitis Foundation of America, Inc.

DOI 10.1002/ibd.21119

Published online 12 October 2009 in Wiley InterScience (www. interscience.wiley.com).
$P<0.001)$, fewer extraintestinal manifestations $(7.7 \%$ versus $24.0 \%, P<0.001)$, and a higher prevalence of proctitis $(32.1 \%$ versus $10.0 \%$ ).

Conclusions: A more aggressive phenotype was found in extensive colitis and in the initial course of younger patients, with an increased need for steroids and immunosuppressors. In addition, a significant percentage of patients, particularly with proctitis, showed a milder clinical evolution and were maintained in remission only with salicylates.

(Inflamm Bowel Dis 2009;16:822-829)

Key Words: ulcerative colitis, follow-up, relapse, medical treatment, surgery

$\mathrm{T}^{\mathrm{h}}$ he incidence and prevalence of ulcerative colitis (UC) varies widely in different countries and from time to time. In Shivananda et al's ${ }^{1}$ European study a north-south gradient was apparent (rates in northern centers were $40 \%$ higher than those in the south), although with less than that previously reported. Concerning the years 1991-1993, the lowest UC incidence was found in Portugal $\left(1.6 / 10^{5}\right.$ in Almada, south of Portugal), but recent data suggest an increase in these numbers following a similar trend in other southern European countries. ${ }^{2}$ The prevalence of UC in Portugal was estimated at 61.8 per $10^{53}$ in 2007 and is midlevel between countries with the highest prevalence estimates and those with the lowest, but apparently heading toward the highest level group. Along with a low incidence, there were also previous data pointing to a milder clinical activity ${ }^{4}$ in comparison with other European countries, but there is a lack of recent local studies confirming this scenario.

Herein, a national cross-sectional study was carried out with patients from most of the hospitals and clinics serving UC patients all over the country. The Montreal Classification was applied in an effort to identify different clinical patterns in terms of medical and surgical needs. To our knowledge this methodology has never been applied in such a large nationwide study. 


\section{MATERIALS AND METHODS}

During a 15-month period (September 2005 to December 2006), Portuguese doctors following patients with inflammatory bowel disease (IBD) had the opportunity to collect general characteristics and clinical data and upload this information to a central database using an online registry (http://www.gedi.med.up.pt/). Patient registration was carried out through a Web-based system with password and user name validated by a scientific committee. The database was approved by national authorities and was supported by the Portuguese IBD Study Group (Grupo de Estudos da Doença Inflamatória Intestinal-GEDII). Seventy doctors from 33 hospitals and small clinics participated in the study. The information was collected from clinical charts during a routine medical examination that was also used to complete the data collection. Several meetings were organized before and during the inclusion period to standardize and clarify the different criteria and parameters to be used and collected.

The diagnostic criteria for UC were based on a suggestive clinical history, associated with endoscopic and histological signs of inflammation of the mucosa, and infectious disease excluded by culture and microscopic stool examination. $^{5}$

For each patient several parameters were collected: date of symptoms onset and diagnosis, type of clinical onset, extent of disease, familial occurrence of IBD, extraintestinal manifestations, duration of involvement, clinical course, use and response to steroids, immunosuppression, biologic treatment, and abdominal and anal surgery. Fever $\left(\geq 37.5^{\circ} \mathrm{C}\right)$, anemia $(\mathrm{Hb} \leq 11.5 \mathrm{~g} / \mathrm{dL})$, and weight loss $(\geq 5 \%)$ were considered constitutional symptoms and only patients submitted to colectomy or proctocolectomy were considered as being submitted to abdominal surgery. For the extent of the lesions, the most proximal level (evaluated by colonoscopy), achieved at any time since the diagnosis, was measured and patients were grouped as having proctitis, left-sided, and extensive colitis. ${ }^{6}$ The clinical course was standardized in three different curves, the first reflecting a disease without relapses after the first episode (remission), the second illustrating a disease with chronic relapsing symptoms (chronic intermittent), and the third with chronic active behavior (chronic continuous). A relapse was defined as an exacerbation of the symptoms that required more intensive medical treatment or surgery. Regarding steroids, only oral or intravenous forms were taken into consideration and steroid resistance was assumed when patients had active disease despite prednisolone up to $1 \mathrm{mg} / \mathrm{kg} /$ day over a 4-week period. Steroid dependency was stipulated as the inability to reduce corticosteroids below the equivalent of $10 \mathrm{mg} /$ day of prednisolone without recurrent active disease, or the need for a second course of steroids in a 6-month period.
Disease severity was defined by the type of treatment administered (adapted from Loftus et $\mathrm{al}^{7}$ ). Patients were categorized into 4 different severity grades: group 1 representing mild disease (patients with no treatment or with salicylates); group 2 for those with moderate to severe disease, drug-responsive (patients treated with steroids, without steroid resistance or steroid dependence); group 3 for severe disease with drug-dependent or drug-refractory behavior (patients treated with steroids, with steroid resistance or steroid dependence or immunosuppressors/biological); and group 4 for patients with medical refractory disease, submitted to surgery.

\section{Statistics}

Patient and disease characteristics, process of care, interventions, and treatments are presented as absolute frequency (number) and relative frequency (percentage) for categorical variables, and as mean and standard deviation (SD) for continuous variables, if a normal distribution is assumed, or as median and interquartile range (IQR: 25th75 th percentile), if normality could not be assumed. The Kolmogorov-Smirnov test was used to test for normality.

When testing hypotheses concerning continuous variables, parametric tests (Student's $t$-test and 1-factor analysis of variance, ANOVA) and nonparametric tests (MannWhitney and Kruskal-Wallis tests) were used accordingly, taking into account normality assumptions and number of groups compared. When testing hypothesis related to categorical variables, chi-square tests and Fisher's exact tests were used as appropriate.

Whenever statistical hypothesis testing was used a significance level of $\alpha=5 \%$ was considered. Statistical analysis was performed using the software Statistical Package for the Social Sciences v. 15.0 for Windows (SPSS, Chicago, IL).

\section{RESULTS}

\section{Demographic Characteristics}

Of the 5893 patients with IBD recorded in the database, 2863 had UC. They came from both tertiary and quaternary hospitals $(48.6 \%)$, as well as from regional hospitals and private practices $(50.7 \%)$. A small percentage $(0.5 \%)$ was included by pediatricians working in pediatric centers. Of the 2863 UC patients, 1619 were female $(56.5 \%)$ and 1244 male, yielding a male-to-female ratio of 0.8 . The female predominance was highest in a younger onset ( $\leq 40$ years, females $60 \%$; $>40$ years, females $51 \%$, $P<0.001)$.

The median age at diagnosis was $37.8 \pm 15.4$ years. In most of the patients the diagnosis was done before 40 years of age (61\%), in $7 \%$ and $5 \%$ of patients UC was diagnosed before 18 and 16 years, respectively (Fig. 1). 
Median disease duration time was $7.8 \pm 7.7$ years; $41.6 \%$ had $0-4$ years after UC onset, 27.1\% 5-9 years, $15.7 \% 10$ 14 years, and finally $15.3 \%$ had more than 15 years. The patient's main complaints were rectal bleeding, diarrhea, and abdominal pain, and $7.6 \%$ had constitutional symptoms. In 15 patients the initial manifestation was extraintestinal.

Seven percent had family history of IBD, that is, a first-degree or a second-degree relative with IBD, varying between $5.4 \%$ in those diagnosed after 40 years and $8.2 \%$ in those diagnosed before $(P<0.02)$.

Regarding smoking status, $7.7 \%$ were active smokers, $16.3 \%$ former smokers, and $76.1 \%$ never smoked.

\section{Association Between Age at Diagnosis and Disease Course}

Patients diagnosed before 16 years of age had a more aggressive phenotype compared to patients diagnosed between 17 and 40, and to those diagnosed after 40. They were characterized by a more chronic active course, extensive colitis (52\% versus $28 \%$ and $24 \%, P<0.001)$, extraintestinal manifestations (26\% versus $18 \%$ and $12 \%, P<$ 0.001 ), need for steroids $(69 \%$ versus $62 \%$ and $57 \%, P=$ $0.007)$, and immunosuppressors (25\% versus $16 \%$ and $10 \%, P<0.001)$. No differences were found regarding surgical requirement.

The mean disease duration at the time of disease history assessment could be a confounding factor and a longer follow-up in younger patients could explain some of the differences; thus, patients with 5 or fewer years and more than 5 years of disease duration were analyzed separately. This analysis showed that most of the differences tend to vanish in patients with more than 5 years of disease (Table 1).

\section{Extent of Disease}

In $21 \%$ of patients the colonic involvement was limited to the rectum (proctitis), in 52\% the inflammation was distal to splenic flexure (left-sided colitis), and in $28 \%$ the involvement was proximal to the splenic flexure (extensive colitis). A similar age at diagnosis was found in these groups: proctitis $(37 \pm 14)$, left-sided colitis $(39 \pm 16)$, and pancolitis ( $35 \pm 16$ years). In contrast, they had different medical and surgical needs, namely, steroids (30.8/ $61.7 / 82.4 \% ; P<0.001)$, immunosuppressors $(1.2 / 12.3 /$ $28 \% ; P<0.001)$ and surgery $(0.3 / 2.5 / 11.2 \% ; P<0.001)$. Furthermore, they also presented a different disease course, with a higher percentage of patients in remission in proctitis than in patients with left-sided colitis (44\%) and pancolitis $(36 \%)(P<0.001)$.

Smoking status did not differ between the 3 groups, with proctitis, left-sided colitis, and pancolitis having respectively $7.7 \%, 7.4 \%$, and $8.1 \%$ of smokers, and $14.3 \%$, $18.9 \%$, and $13.5 \%$ of former smokers.

\section{Medical and Surgical Treatment}

Salicylates were used in almost $98 \%$ of the patients, and in a significant proportion, $38 \%$ were the only drug used in treatment. Eighty-four percent used these drugs in maintenance therapy, mainly in oral $(47.6 \%)$ or in oral plus topical administration $(27.7 \%)$.

Moreover, a total of $1700(60 \%)$ had taken steroids at least once: $398(14 \%)$ immunosuppressors and $38(1 \%)$ biologic agents. Eighty-seven $(5.1 \%)$ were considered steroid-resistant and 293 (17.2\%) steroid-dependent.

Among patients treated with steroids, $66 \%$ were never considered corticodependent, corticoresistant, were never treated with an immunosuppressor (even if they did not fulfill criteria for dependency or resistance to steroids), or submitted to surgery.

The immunosuppressors most used in clinical practice were azathioprine and 6-mercaptopurine $(92 \%$ and $3.6 \%$ respectively). A small proportion had been treated with methotrexate or cyclosporine (2.1\%).

In all, 125 patients $(4.5 \%)$ were submitted to surgery, mostly due to an acute severe flare or chronic relapsing disease $(90.4 \%)$. In $9.6 \%$ of the cases the motive for colectomy was colorectal cancer/dysplasia. Higher rates of surgery were observed in males (59\% versus $43 \%$ in nonsurgical patients, $P<0.001$ ), in those with constitutional symptoms at diagnosis $(17 \%$ versus $8 \%, P=0.001)$, and in extensive colitis patients (69\% versus $25 \%, P<0.001$ ).

On the other hand, the group of patients treated only with salicylates (and without surgery) was characterized by a slightly older age at diagnosis, fewer systemic symptoms at presentation, a higher prevalence of proctitis, and fewer extraintestinal manifestations. Due to the large percentage of patients with less than 5 years of disease duration in this age group, additional analysis restricted to those with 5 or more years of disease was performed. In these patients, $31 \%$ (486 out of 1553) were treated only with salicylates and were characterized, as a whole population, by a lower incidence of systemic symptoms at presentation $(3.8 \%$ versus $8.8 \%, P<0.001$ ), fewer extraintestinal manifestations (7.7\% versus $24.0 \%, P<0.001)$, and a higher percentage of proctitis $(32.1 \%$ versus $10.0 \%, P<0.001)$.

\section{Disease Severity Over Time}

The population was stratified by the number of years of disease duration and 6 different subgroups were considered. In total, 281 patients had $<1$ year, 850 patients with 1-4 years of disease duration, 737 with 5-9 years, 428 with 10-14 years, 183 with $15-19$ years, 135 with $20-24$ years, and 103 with at least 25 years of disease duration. Forty-three percent (1172) of the patients did not have 


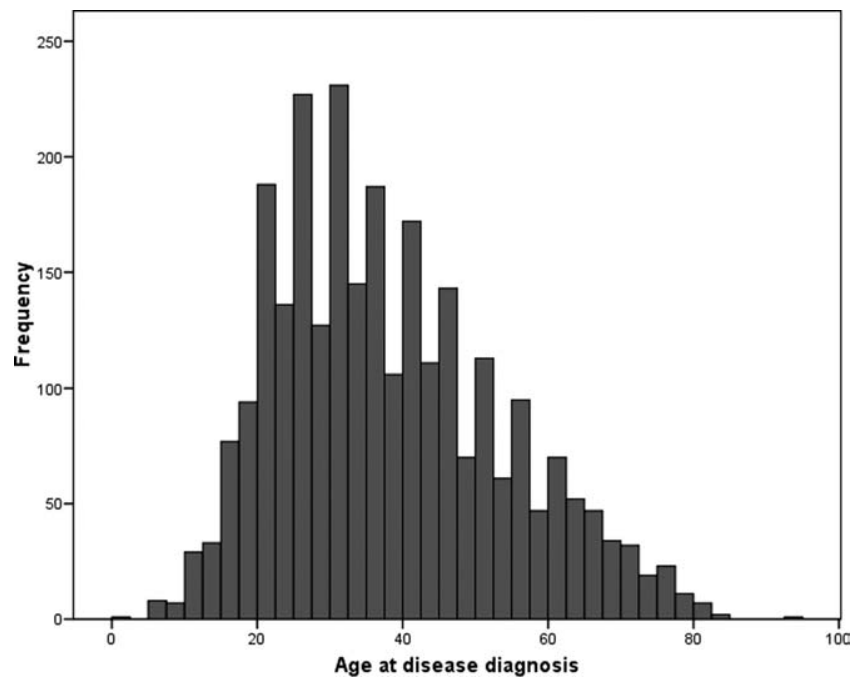

FIGURE 1. Age at diagnosis.

relapses after diagnosis (i.e., new symptoms justifying the need for more intensive medical treatment or surgery) and were considered in remission, whereas $49.4 \%$ had chronic intermittent symptoms, and $7.4 \%$ had a chronic continuous behavior. These groups (remission, chronic intermittent, and continuous course) had different demographic and clin- ical traits, namely, different age at diagnosis, clinical presentation, and extent of disease (Table 2). Furthermore, as a reflection of their diversity in disease severity, they had different therapeutic needs, namely, steroids (43/71/92\%), immunosuppressors (3/17/58\%), and surgery (2.4/3.2/ 24.1\%).In addition, time after diagnosis was similar between the groups (remission $7.3 \pm 7.4$; chronic intermittent $8.5 \pm 8$; and chronic continuous $7.6 \pm 6.6$ years).

Considering the 4 grades of disease severity previously mentioned, a trend toward an increasing severity was found among patients with disease duration of 0-10 years, followed by a steady state (Fig. 2). The percentage of patients in group 1 (i.e., no treatment or salicylates) decreased from $51 \%$ in those with less than 5 years of disease duration, to $34 \%$ in patients with 5-9 years, and during the same period the percentage of patients in groups 2 and 3 increased from $32 \%$ to $40 \%$ and from $13 \%$ to $20 \%$, respectively.

\section{DISCUSSION}

Although this study was mostly hospital-based, it included several characteristics that reduced the likelihood of bias associated with a typical tertiary center-referred population, with a poorer prognosis than that found in population-based studies. Based on salicylate consumption in

TABLE 1. Age at Diagnosis, Demographics, and Clinical Characteristics of UC Patients

\begin{tabular}{|c|c|c|c|c|c|c|c|c|c|c|}
\hline & \multicolumn{10}{|c|}{ Time After Diagnosis } \\
\hline & \multicolumn{5}{|c|}{$\leq 5$ years } & \multicolumn{5}{|c|}{$>5$ years } \\
\hline & \multicolumn{3}{|c|}{ Age at Diagnosis } & \multirow{3}{*}{$\begin{array}{l}\text { Total } \\
n(\%)\end{array}$} & \multirow{3}{*}{$P$-value ${ }^{\mathrm{a}}$} & \multicolumn{3}{|c|}{ Age at Diagnosis } & \multirow{3}{*}{$\begin{array}{l}\text { Total } \\
n(\%)\end{array}$} & \multirow{3}{*}{$P$-value ${ }^{\mathrm{a}}$} \\
\hline & $\leq 16$ & $17-40$ & $>40$ & & & $\leq 16$ & $17-40$ & $>40$ & & \\
\hline & $n(\%)$ & $n(\%)$ & $\mathrm{n}(\%)$ & & & $n(\%)$ & $n(\%)$ & $n(\%)$ & & \\
\hline \multicolumn{11}{|l|}{ Sex } \\
\hline Male & $16(33)$ & $299(43)$ & $295(53)$ & $610(47)$ & \multirow[t]{2}{*}{$<0.001^{\mathrm{b}}$} & $28(35)$ & $322(39)$ & $221(45)$ & $571(41)$ & \multirow[t]{2}{*}{$0.066^{\mathrm{b}}$} \\
\hline Female & $33(67)$ & $397(57)$ & $261(47)$ & $691(53)$ & & $53(65)$ & $501(61)$ & $273(55)$ & $827(59)$ & \\
\hline \multicolumn{11}{|l|}{ Clinical presentation } \\
\hline With constitutional symptoms & $9(18)$ & $46(7)$ & $46(8)$ & $101(8)$ & \multirow[t]{2}{*}{$0.013^{\mathrm{b}}$} & $10(12)$ & $56(7)$ & $19(4)$ & $85(6)$ & \multirow[t]{2}{*}{$0.006^{\mathrm{b}}$} \\
\hline Without constitutional symptoms & $40(82)$ & $634(93)$ & $501(92)$ & $1175(92)$ & & $71(88)$ & $749(93)$ & $460(96)$ & $1280(94)$ & \\
\hline \multicolumn{11}{|l|}{ Extent of disease } \\
\hline Proctitis & $6(12)$ & $185(27)$ & $124(22)$ & $315(24)$ & \multirow[t]{3}{*}{$<0.001^{\mathrm{b}}$} & $11(14)$ & $154(19)$ & $80(16)$ & $245(18)$ & \multirow[t]{3}{*}{$<0.001^{\mathrm{b}}$} \\
\hline Left-sided colitis & $17(35)$ & $333(48)$ & $298(54)$ & $648(50)$ & & $29(36)$ & $414(51)$ & $295(60)$ & $738(53)$ & \\
\hline Pancolitis & $26(53)$ & $175(25)$ & $131(24)$ & $332(26)$ & & $41(51)$ & $251(31)$ & $118(24)$ & $410(29)$ & \\
\hline Extraintestinal manifestations & $12(25)$ & $104(15)$ & $50(9)$ & $166(13)$ & $<0.001^{\mathrm{b}}$ & $22(27)$ & $165(20)$ & $76(16)$ & $263(19)$ & $0.016^{\mathrm{b}}$ \\
\hline Steroid therapy & $30(61)$ & $375(55)$ & $269(49)$ & $674(52)$ & $0.057^{\mathrm{b}}$ & $58(73)$ & $555(69)$ & $325(67)$ & $938(68)$ & $0.437^{\mathrm{b}}$ \\
\hline Immunosuppression & $17(35)$ & $107(16)$ & $42(8)$ & $166(13)$ & $<0.001^{\mathrm{b}}$ & 15 (19) & $134(16)$ & $64(13)$ & $213(15)$ & $0.192^{\mathrm{b}}$ \\
\hline Abdominal surgery & $2(4)$ & $20(3)$ & $13(2)$ & $35(3)$ & $0.728^{\mathrm{b}}$ & $7(9)$ & $52(6)$ & $24(5)$ & $83(6)$ & $0.333^{b}$ \\
\hline
\end{tabular}


TABLE 2. Clinical Course Related to Demographic and Clinical Characteristics of UC Patients

\begin{tabular}{|c|c|c|c|c|}
\hline & $\begin{array}{l}\text { Remission }(N=1172) \\
\text { Column } \% /(\text { Line } \%)\end{array}$ & $\begin{array}{c}\text { Chronic Intermittent } \\
(N=1313) \\
\text { Column } \% /(\text { Line } \%)\end{array}$ & $\begin{array}{c}\text { Chronic Continuous } \\
(N=198) \\
\text { Column \% / (Line \%) }\end{array}$ & $P$-value \\
\hline \multicolumn{5}{|l|}{ Age at diagnosis } \\
\hline$($ media $\pm \mathrm{SD})$ & $40 \pm 16$ & $36 \pm 15$ & $35 \pm 15$ & \multirow[t]{3}{*}{$P<0.001^{\mathrm{a}}$} \\
\hline$\leq 16$ years & $4.8 \% /(44.7 \%)$ & $4.7 \% /(47.2 \%)$ & $5.2 \% /(8.1 \%)$ & \\
\hline $17-40$ years & $48,9 \% /(38.6 \%)$ & $62.1 \% /(52.7 \%)$ & $64.8 \% /(8.7 \%)$ & \\
\hline$>40$ years & $46.2 \% /(53.1 \%)$ & $33.2 \% /(41.0 \%)$ & $30.1 \% /(5.8 \%)$ & $P<0.001^{\mathrm{b}}$ \\
\hline \multicolumn{5}{|l|}{ Sex } \\
\hline Male/female & $\begin{array}{c}44.6 / 55.4 \% / \\
(44.5 / 43.1 \%)\end{array}$ & $\begin{array}{l}42.2 / 57.8 \% / \\
(47.1 / 50.4 \%)\end{array}$ & $\begin{array}{c}50.0 / 50.0 \% / \\
(8.4 / 6.6 \%)\end{array}$ & $P=0.091^{\mathrm{b}}$ \\
\hline \multicolumn{5}{|l|}{ Clinical presentation } \\
\hline With constitutional symptoms & $5.3 \% /(31.2 \%)$ & $7.6 \% /(49.7 \%)$ & $19.3 \% /(19.1 \%)$ & \multirow[b]{2}{*}{$P<0.001^{\mathrm{b}}$} \\
\hline Without constitutional symptoms & $94.7 \% /(44.7 \%)$ & $92.4 \% /(48.9 \%)$ & $80.7 \% /(6.4 \%)$ & \\
\hline \multicolumn{5}{|l|}{ Extent of disease } \\
\hline Proctitis & $26.0 \% /(54.0 \%)$ & $18.9 \% /(43.9 \%)$ & $6.1 \% /(2.1 \%)$ & \multirow{3}{*}{$P<0.001^{\mathrm{b}}$} \\
\hline Left-sided colitis & $51.6 \% /(43.5 \%)$ & $53.4 \% /(50.4 \%)$ & $42.6 \% /(6.1 \%)$ & \\
\hline Pancolitis & $22.3 \% /(36.0 \%)$ & $27.7 \% /(50.1 \%)$ & $51.3 \% /(13.9 \%)$ & \\
\hline
\end{tabular}

2005 and considering a daily drug intake-defined dose (DDD) of $2 \mathrm{~g} /$ day, half of the UC patients in Portugal were considered included in this study, ${ }^{3}$ but more important, patients were not only recruited from university hospitals and tertiary hospitals, but also from smaller hospitals and even from small clinics and private practices.

In this study a slight female preponderance was detected, which tends to diminish in older patients, where the ratio between males and females approaches 1 . This is in accordance with other studies ${ }^{1,8}$ that found a less pronounced peak-age-specific incidence in men. Moreover, in pediatric patients a higher male-to-female ratio was not demonstrated, which seems to be confined to Crohn's disease (CD). ${ }^{9}$

The low rate of family history $(7,2 \%)$, found in Portuguese patients could reflect an increasing incidence of IBD, among a population not considered at high risk in the past, but now facing new environmental factors.

The importance of age at disease onset as a factor in UC is insufficiently studied. In CD there is clear evidence showing that early-onset represents a distinct and more aggressive phenotype, ${ }^{10}$ with greater need for surgery; however, in relation to UC the data are scarce. In this cross-sectional study, by applying the same stratification for the variable age at disease onset as the Montreal Classification for $\mathrm{CD}$, younger patients seem to have a more aggressive initial course, with a higher rate of extraintestinal manifestations, pancolitis, and the need for steroids and immunomodulators. This pattern is similar to CD and is in accordance with some publications indicating a higher rate of relapse in patients diagnosed at earlier ages. ${ }^{11-13}$ However, when patients are restricted according to disease duration, i.e., more than 5 years of follow-up, the differences tended to disappear and lose statistical significance. These data sustain the notion that a young age at diagnosis in UC does not imply a more severe prognosis and does not support its immediate inclusion in the UC classification.

Regarding disease extent, the maximum limit and not extent at diagnosis was chosen because previous studies showed that the initial extent did not affect the subsequent activity course. This approach clearly defined 3 different groups, with proctitis showing a significantly less aggressive phenotype. As such, patients were defined according to medical or surgical needs, or by the percentage of patients in remission versus patients with a chronic intermittent or continuous behavior. Pancolitis had the most severe behavior, and distal colitis occupied an intermediate position, representing respectively $69 \%$ and $29 \%$ of patients submitted to surgery. These differences clearly demonstrate the importance of disease extent, currently considered a biological marker. ${ }^{14}$ 


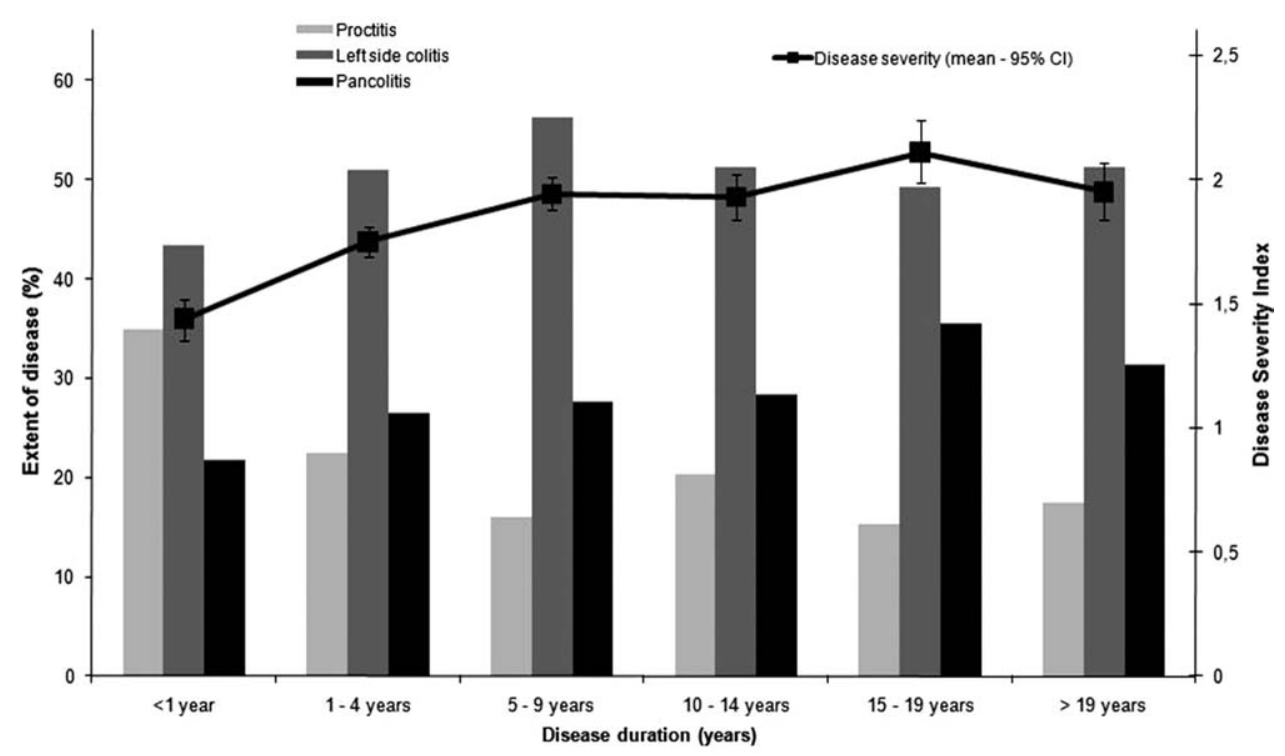

FIGURE 2. Disease extent according to the Montreal Classification and disease severity in different intervals of disease duration. Relative frequency (percentage) for each disease extension category (left axis) and disease severity index (right axis) classified in 4 disease severity categories defined by the type of treatment administered (adapted from Loftus et $\mathrm{al}^{7}$ ).

Despite the negative correlation of smoking with UC incidence, ${ }^{15}$ predominantly affecting nonsmokers and former smokers, there are previous reports showing the influence of smoking on disease extent and on the clinical course. In this study less than $8 \%$ (7.7) were active smokers, which is significantly less than the average $19.7 \%$ for the Portuguese population (National Institute of Statistics, www.ine.pt). In fact, in contrast to previous reports, ${ }^{16}$ no correlation between smoking status and disease extent, determined as the most proximal level achieved at any time during disease course, was found. This could reflect previous information that revealed that these differences were not maintained over a long time period. ${ }^{17}$

In contrast to recent series from countries traditionally reported as regions of low incidence and milder disease, ${ }^{18}$ and similar to data found in Western populations, $14 \%$ of the patients needed immunosuppressors and $60 \%$ had taken steroids.

Due to corticoresistance, corticodependence, or need of immunosuppressors, $34 \%$ of patients treated with corticosteroids can be considered steroid failures in the long term. Although different definitions and time frames were applied, this percentage was similar to what was found by others, ${ }^{19}$ where $38 \%$ of patients were considered corticodependent or needing alternative treatments, namely, surgery.

Notwithstanding, one must consider the large proportion of patients (almost 40\%) solely treated with salicylates before discussing therapeutic strategies such as a more widespread use of immunosuppressors/biologicals or a top- down approach. This group is noteworthy due to its high percentage of proctitis.

Although the use of biologics is scarce, $1 \%$, this is primarily thought to be associated with regulatory reasons. The study only included patients until December 2006, precisely the year infliximab was approved for UC by the EMEA, and therefore the small number of patients treated with biologicals is due mostly to patients treated off-label with the drug.

In relation to surgical needs, we found a colectomy rate $(4.5 \%)$ lower than most previously reported, ${ }^{20}$ but comparable to data from the European multicenter study, ${ }^{21}$ especially for the southern European centers included (3.9\% at 10 years) and 4 times higher than what was previously reported for Portugal. ${ }^{4}$ There is no clear explanation for this fact, although one could speculate that this is due to differences in patients' and in physicians' perspectives of disease activity and indications for surgery. As in the previously mentioned study, ${ }^{21}$ extent of disease was an important predictive factor for colectomy, i.e., $0.3 \%$ for proctitis and $11.2 \%$ for pancolitis. Nevertheless, both percentages were lower than that previously reported in studies, especially from the north of Europe and USA, excluding a high percentage of extensive colitis as a direct explanation for the differences in colectomy rates. We also did not find any significant differences in the indication for surgery, with more than $90 \%$ of our patients submitted for medical refractory disease and only a small percentage for cancer/ dysplasia. 
The disease course of UC was previously described as remission, chronic intermittent, and continuous course. ${ }^{22}$ While a significant number of patients were in remission at each year, on a long-term basis the vast majority had additional symptoms.

In the past the natural history of UC in Portugal (from a reference university hospital) was reported as mild or moderate in more than $75 \%$ of patients, with $1.1 \%$ of colectomies over a 14.5 -year period. ${ }^{4}$

The overall relapse rate in this study, in which patients had a median follow-up of 7.8 years, was $57 \%$. This is remarkably less than what was found by some authors, ${ }^{20,22,23}$ but similar to recent reports, particularly the multicenter European study. ${ }^{10}$ In this study a cumulative relapse rate of $57 \%(53 \%-61 \%)$ at 5 years and $67 \%$ $(63 \%-71 \%)$ at 10 years were reported. These data indicate that there is a large proportion of patients with a disease course characterized by a decrease in symptoms during the follow-up period, in accordance with the patient's perception of their disease as described in the IBSEN study. ${ }^{24}$ In that study, 59\% of 420 Norwegian patients with UC chose a disease curve reflecting a decrease in symptoms over time.

In conclusion, this study showed that a large proportion of UC patients were symptom-free or had remarkable symptomatic improvement several years after the diagnosis. Furthermore, a more aggressive phenotype was detected in extensive colitis and, to a lesser extent, in younger patients with increased need for steroids and immunosuppressors.

\section{ACKNOWLEDGMENT}

GEDII: Amadeu Corte Real Nunes; Ana Isabel Valente; Ana Isabel Vieira; Antónia Duarte; António Marques; Antonio Queiroz; Bernardino Ribeiro; Carolina Duesca; Celeste Fátima Viveiros; Cidalina Caetano; Claudia Sequeira; David Horta; Edgar Gencsi; Estela Monteiro; Fernando Magro; Filipe Gomes Silva; Francisco Portela; Glória Marinho; Helder Cardoso; Helena Vasconcelos; Helena Sousa; Henrique Morna; Horácio Lopes; Isabel Bastos; Isabel Medeiros; Isabel Seves; Isadora Rosa; João Baranda; João Ramos de Deus; Jorge Amil Dias; J Godinho Lopes;; João Freitas;; J. Pinto de Matos; Jorge Reis; Jorge Vieira; Jose Cotter; José Estevens; J M Ribeiro; Laura Carvalho; Leopoldo Matos; Luís Correia; Luís Jasmins; Luís Lebre; Luísa Barros; Luísa Gloria; Lurdes Tavares; Marília Cravo; Margarida Marques; Marie Isabelle Cremers; Maria do Rosário Maldonado; Manuel Correia; Maria de Lurdes Gonçalves; Mário César; Miguel Areia; Manuela Ferreira; Mário Júlio Campos; Marta Salgado; Nuno Almeida; Paulo Andrade; Paula Lago; Paula Ministro; Paula Moura Santos; Paula Peixe; Paulo Caldeira; Paulo Freire; Pedro Martins;
Raquel Gonçalves; Ricardo Ferreira; Ricardo Freire; Rui Loureiro; Rui Sousa; Rute Cerqueira; Salazar Sousa; Salomé Costa Lima; Sara Folgado Alberto; Silvia Leite; Sofia Mendes; Sónia Barroso; Sandra Lopes; Sónia Nobre; Susana Rodrigues, Tiago Bana e Costa; Vítor Fernandes.

\section{REFERENCES}

1. Shivananda S, Lennard-Jones J, Logan R, et al. Incidence of inflammatory bowel disease across Europe: is there a difference between north and south? Results of the European Collaborative Study on Inflammatory Bowel Disease (EC-IBD). Gut. 1996;39: 690-697.

2. Tragnone A, Corrao G, Miglio F, et al. Incidence of inflammatory bowel disease in Italy: a nationwide population-based study. Gruppo Italiano per lo Studio del Colon e del Retto (GISC). Int J Epidemiol. 1996;25:1044-1052.

3. Magro F, Portela F, Lago P, et al. A Pharmaco-epidemiological approach to estimate IBD prevalence and incidence in Portugal. J Crohn's Colitis. 2008;2:35.

4. Tavarela Veloso F, Fraga J, Carvalho J. Inflammatory bowel disease in Oporto. A prospective hospital study. Scand J Gastroenterol Suppl. 1989; 170:32-35

5. Lennard-Jones JE. Classification of inflammatory bowel disease. Scand J Gastroenterol Suppl. 1989;170:2-6.

6. Satsangi J, Silverberg MS, Vermeire S, et al. The Montreal classification of inflammatory bowel disease: controversies, consensus, and implications. Gut. 2006;55:749-753.

7. Loftus EV Jr, Schoenfeld P, Sandborn WJ. The epidemiology and natural history of Crohn's disease in population-based patient cohorts from North America: a systematic review. Aliment Pharmacol Ther. 2002; 16:51-60.

8. Gower-Rousseau C, Salomez JL, Dupas JL, et al. Incidence of inflammatory bowel disease in northern France (1988-1990). Gut. 1994;35: $1433-1438$.

9. Kugathasan S, Judd RH, Hoffmann RG, et al. Epidemiologic and clinical characteristics of children with newly diagnosed inflammatory bowel disease in Wisconsin: a statewide population-based study. $J$ Pediatr. 2003;143:525-531.

10. Polito JM, 2nd, Childs B, Mellits ED, Tokayer AZ, Harris ML, Bayless TM. Crohn's disease: influence of age at diagnosis on site and clinical type of disease. Gastroenterology. 1996;111: $580-586$.

11. Satsangi J, Silverberg MS, Vermeire S, et al. The Montreal classification of inflammatory bowel disease: controversies, consensus, and implications. Gut. 2006;55;749-753.

12. Höie O, Wolters F, Riis L, et al. European Collaborative Study Group of Inflammatory Bowel Disease (EC-IBD). Ulcerative colitis: patient characteristics may predict 10 -yr disease recurrence in a Europeanwide population-based cohort. Am J Gastroenterol. 2007;102: 1692-1701.

13. Moum B, Ekbom A, Vatn MH, et al. Clinical course during the 1st year after diagnosis in ulcerative colitis and Crohn's disease. Results of a large, prospective population-based study in southeastern Norway, 1990-93. Scand J Gastroenterol. 1997;32: 1005-1012.

14. Bitton A, Peppercorn MA, Antonioli DA, et al. Clinical, biological, and histologic parameters as predictors of relapse in ulcerative colitis. Gastroenterology. 2001;120:13-20.

15. Calkins BM. A meta-analysis of the role of smoking in inflammatory bowel disease. Dig Dis Sci. 1989;34:1841-1854.

16. Mokbel M, Carbonnel F, Beaugerie L, et al. Effect of smoking on the long-term course of ulcerative colitis. Gastroenterol Clin Biol. 1998; 22:858-862.

17. Aldhous MC, Drummond HE, Anderson N, et al. Smoking habit and load influence age at diagnosis and disease extent in ulcerative colitis. Am J Gastroenterol. 2007;102:589-597. 
18. Park SH, Kim YM, Yang SK, et al. Clinical features and natural history of ulcerative colitis in Korea. Inflamm Bowel Dis. 2007;13: $278-283$.

19. Ho GT, Chiam P, Drummond H, et al. The efficacy of corticosteroid therapy in inflammatory bowel disease: analysis of a 5-year UK inception cohort. Aliment Pharmacol Ther. 2006;24:319-330

20. Langholz E, Munkholm P, Davidsen M, et al. Course of ulcerative colitis: Analysis of changes in disease activity over years. Gastroenterology. 1994;107:3-11.

21. Selby W. The natural history of ulcerative colitis. Baillieres Clin Gastroenterol. 1997;11:53-64.
22. Stewenius J, Adnerhill I, Ekelund GR, et al. Risk of relapse in new cases of ulcerative colitis and indeterminate colitis. Dis Colon Rectum. 1996;39:1019-1025.

23. Henriksen M, Jahnsen J, Lygren I, et al. IBSEN Study Group. Ulcerative colitis and clinical course: results of a 5-year population-based follow-up study (the IBSEN study). Inflamm Bowel Dis. 2006;12: $543-550$.

24. Hoie O, Wolters FL, Riis L, et al. European Collaborative Study Group of Inflammatory Bowel Disease. Low colectomy rates in ulcerative colitis in an unselected European cohort followed for 10 years. Gastroenterology. 2007;132:507-515. 